\title{
Ameloblastic carcinoma in a young patient
}

Davide Sozzi, MD, ${ }^{a}$ Valeria Morganti, MD, ${ }^{\mathrm{a}}$ Gabriella Maria Valente, MD, ${ }^{\mathrm{b}}$ Francesca Moltrasio, MD, ${ }^{\mathrm{b}}$ Alberto Bozzetti, MD, ${ }^{a}$ and Francesca Angiero, $\mathrm{MD}^{\mathrm{c}}$

University of Milan-Bicocca, Milan; Hospital San Gerardo, Monza; and University of Genoa, Genoa, Italy

Owing to the rarity of publications describing ameloblastic carcinoma, little is known about this entity in pediatric patients. To our knowledge, malignant transformation from an odontogenic cyst into an ameloblastic carcinoma in a pediatric patient has not been documented to date. We present the case of a 14-year-old boy in whom a large osteolytic lesion associated with an impacted right maxillary third molar germ was fortuitously detected by orthopanoramic radiography. With a preoperative clinical-radiographic diagnosis of odontogenic cyst, the patient underwent surgical enucleation of the lesion. Histologic evaluation rendered a diagnosis of follicular cyst with a focal area of ameloblastic carcinoma. The literature addressing ameloblastic carcinoma is reviewed. (Oral Surg Oral Med Oral Pathol Oral Radiol 2014;117:e396-e402)

Odontogenic tumors originate from epithelial, ectomesenchymal, or mesenchymal tissues that are, or have been, part of the tooth-forming apparatus. Such tumors are thus exclusively found within the maxillofacial skeleton (intraosseous or centrally located), in the soft tissue overlying tooth-bearing areas, or in the alveolar mucosa in edentulous regions (extraosseous or peripherally located). Onset may be at any age. ${ }^{1}$

Odontogenic malignancies are $1 \%$ of all cysts and tumors occurring in the jaws. ${ }^{2,3}$ In the 2005 World Health Organization classification (Table I), the ameloblastic carcinoma is defined as a rare primary odontogenic malignancy that combines the histologic features of ameloblastoma with cytologic atypia. This definition applies even in the absence of metastasis. ${ }^{1}$

Microscopically, ameloblastic carcinoma shows characteristics of ameloblastic differentiation, cellular nests with peripheral palisading of basaloid cells, associated with a central discohesive component, forming stellate reticulum-like areas. The malignant nature of the lesion is revealed by marked nuclear atypia, mitotic figures, an infiltrative growth pattern, and association with the presence of disordered sheets and islands of epithelium.

We present a case of pediatric ameloblastic carcinoma arising in a follicular cyst. The literature addressing the ameloblastic carcinoma is reviewed and discussed.

\footnotetext{
${ }^{\mathrm{a} D e p a r t m e n t}$ of Maxillofacial Surgery, University of Milan-Bicocca and Hospital San Gerardo.

${ }^{\mathrm{b}}$ Department of Pathology, University of Milan-Bicocca and Hospital San Gerardo.

${ }^{\mathrm{c} D e p a r t m e n t ~ o f ~ S u r g i c a l ~ M e d i c a l ~ S c i e n c e s ~ a n d ~ D i a g n o s t i c ~ I n t e g r a t e d, ~}$ University of Genoa.

Received for publication Feb 4, 2013; returned for revision Jul 30, 2013; accepted for publication Aug 18, 2013.

(c) 2014 Elsevier Inc. All rights reserved.

$2212-4403 / \$$ - see front matter

http://dx.doi.org/10.1016/j.00oo.2013.08.012
}

Table I. World Health Organization classification of odontogenic malignancies (2005)
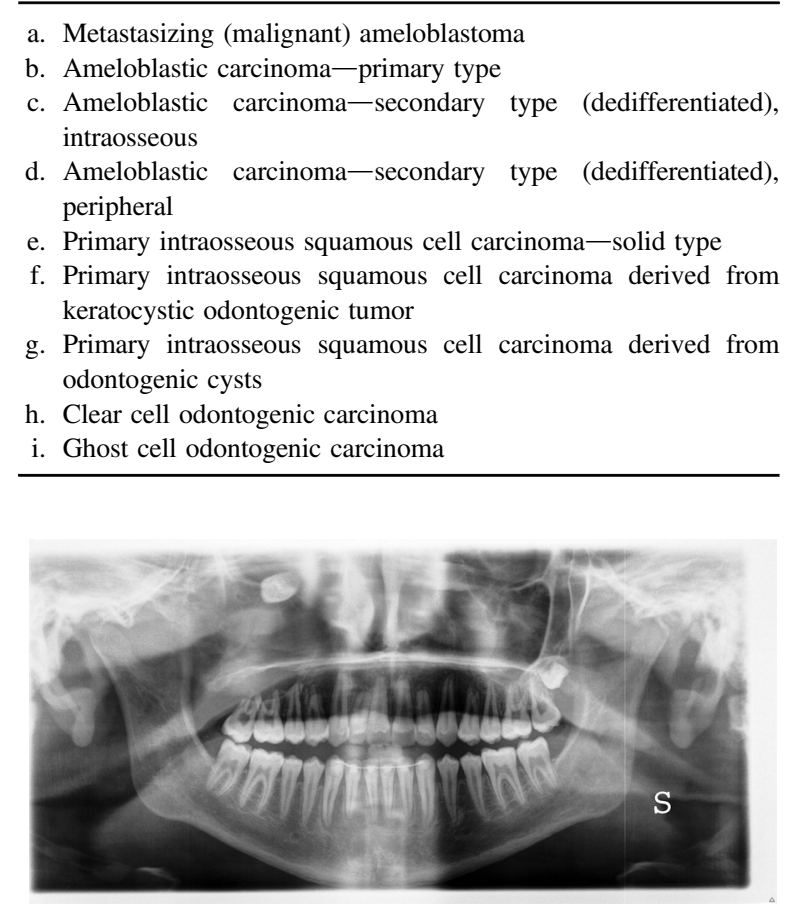

Fig. 1. Orthopanoramic radiography revealed a large osteolytic lesion within an impacted right maxillary third molar germ.

\section{CASE REPORT}

In September 2010, during routine orthopanoramic radiography, a large osteolytic lesion associated with an impacted right maxillary third molar was detected in a 14-year-old boy (Figure 1). The patient was referred to the Maxillo-Facial Surgery Department, Monza San Gerardo Hospital, University of Milan-Bicocca School of Medicine, for evaluation and treatment. On examination, the patient's general health was good. Intraoral examination revealed a right maxillary swelling with intact overlying mucosa. No trigeminal paresthesia was noted. The right maxillary first and second molars 


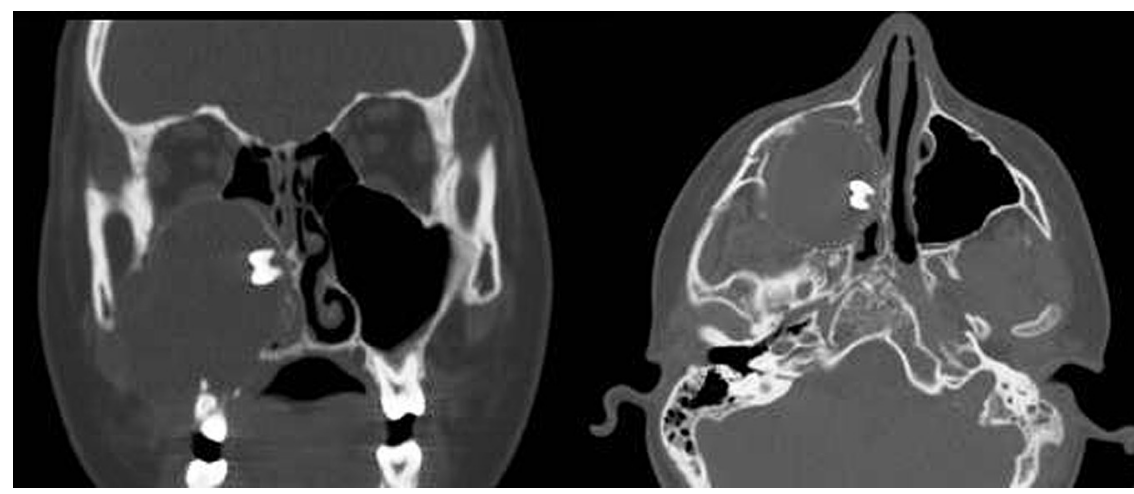

Fig. 2. Computed tomography. Coronal section (right) shows a large cystic lesion of the maxilla. Axial section (left) shows a radiolucent area occupying a large portion of the right maxillary sinus, extending into the nasal cavity.

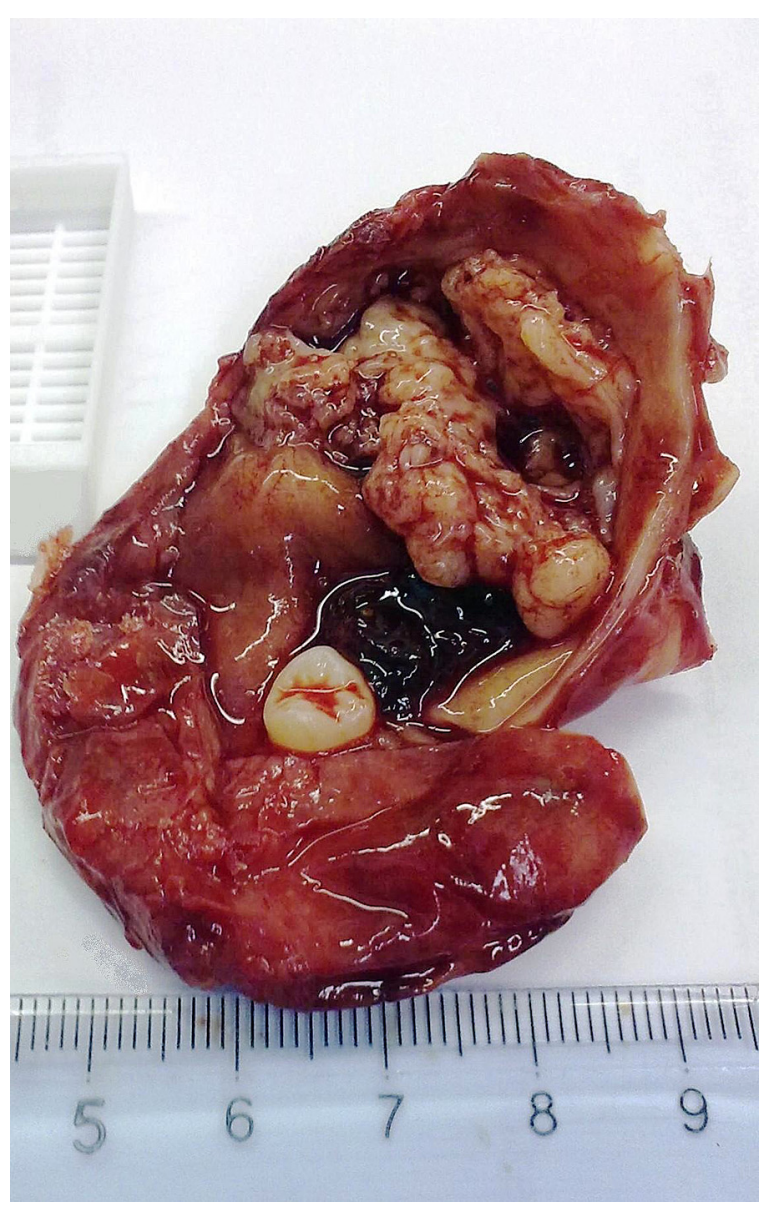

Fig. 3. At macroscopic examination, the tumor comprised a cystic mass containing within it an impacted tooth and considerable cellular debris, with vegetation adherent to the inner surface.

were mobile. Computed tomography (CT) scanning revealed a large maxillary cystic lesion, involving the alveolar bone, maxillary sinus and nasal cavity, with no soft tissue extension, containing the right maxillary third molar germ medially (Figure 2). The clinical and radiologic presentation and the patient's age were suggestive of a follicular cyst.

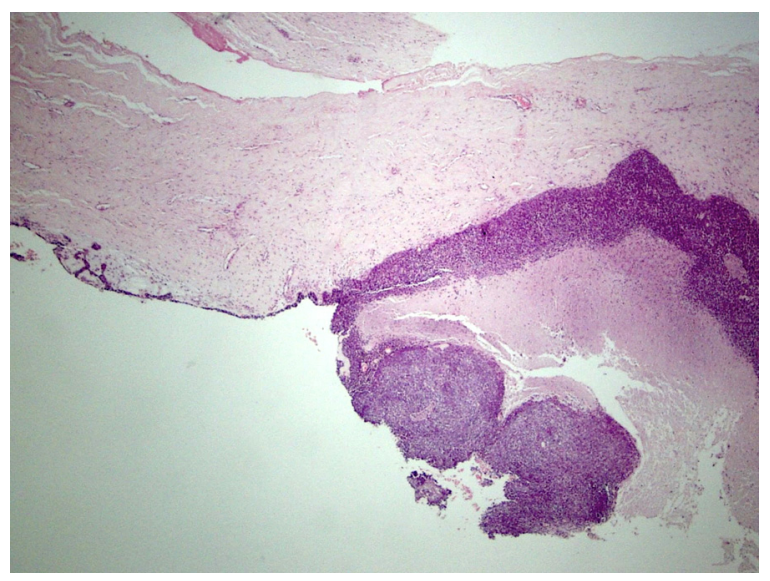

Fig. 4. Photomicrograph showing the transition from conventional bland-appearing cystic epithelium (consistent with dentigerous cyst) to an area which exhibits ameloblastomatous features (hematoxylin-eosin, original magnification $\times 10$ ).

Intraoral surgical enucleation was performed. Parts of the cortical bone were removed where they were very thin. The third-molar germ was contained within the cystic lesion.

The surgical material was sent to the Oral Pathology Department. The tumor comprised a cystic mass with adherent thin bony plates, containing within it an impacted tooth and considerable cellular debris. Vegetations adherent to the inner surface were present (Figure 3). Microscopically, on hematoxylin-eosin staining, the histologic sections revealed a cystic structure lined with odontogenic epithelium of variable thickness, composing a focal odontogenic tumor of epithelial origin made up of cellular elements resembling ameloblasts (Figures 4 to 6). These cellular elements, medium-sized to large, had voluminous and hyperchromatic nuclei and clear cytoplasm arranged in nests, with central areas of necrosis and peripheral areas of odontogenic epithelium. Cells showed marked cytologic atypia and loss of normal nuclear polarization (Figure 7). Five mitotic figures per 10 high-power fields were noted. The immunohistochemical (IHC) profile showed a positive reaction for cytokeratin AE1/AE3, smooth muscle actin, and Ki-67 proteins 


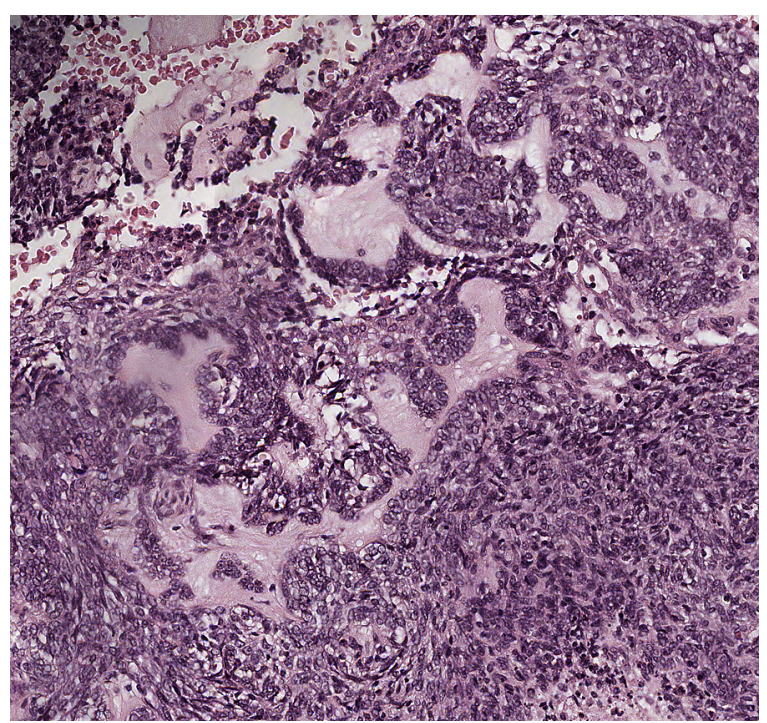

Fig. 5. Photomicrograph showing follicular growth pattern with stellate reticulum-like structure and central necrosis. Peripheral columnar cells are palisaded in the follicular islands (hematoxylin-eosin, original magnification $\times 20$ ).

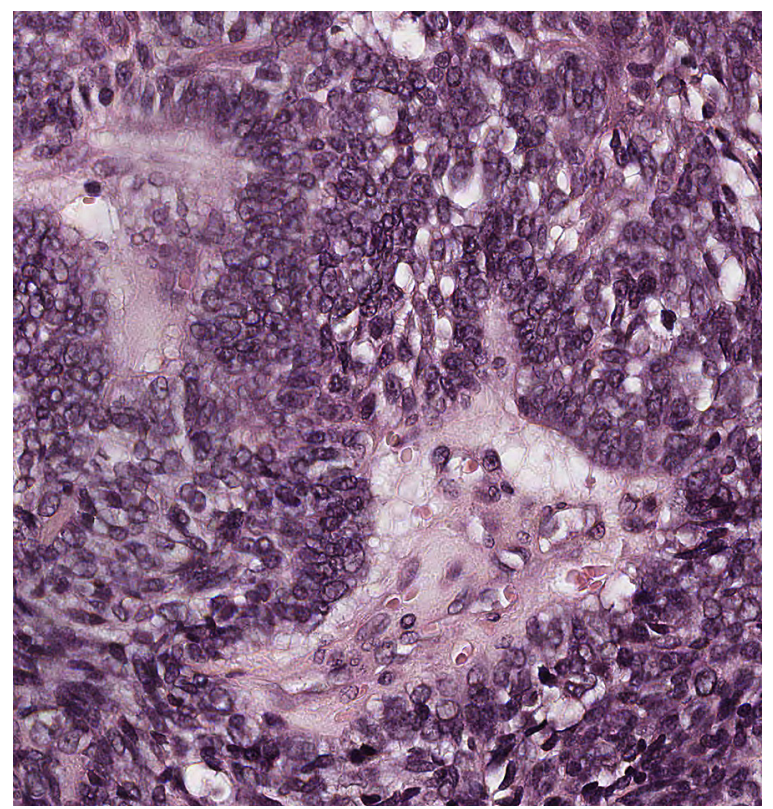

Fig. 6. Photomicrograph showing tumor cells with hyperchromatism, nuclear pleomorphism, and mitotic figures. Central necrosis is also visible (hematoxylin-eosin, original magnification $\times 10$ ).

(Figures 8 to 10). Focal positivity was found for calponin. IHC was negative for S-100, p53, and vimentin proteins.

The final diagnosis was follicular cyst with a focal area of ameloblastic carcinoma.

Based on this diagnosis, the patient was scheduled for head and neck CT, chest radiography, bone scintigraphy, and abdominal ultrasonography to rule out metastases. Based on

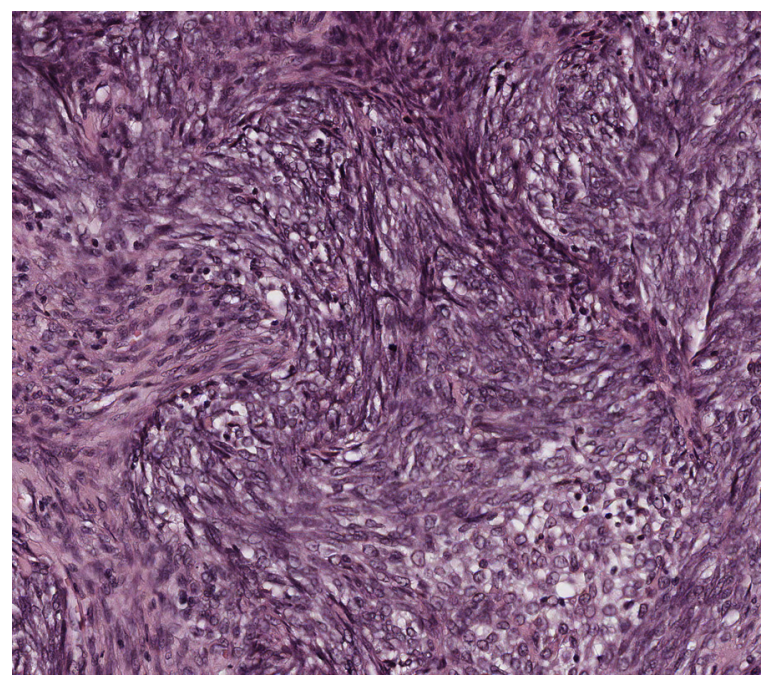

Fig. 7. Photomicrograph showing a proliferative area characterized by hypercellular nests of epithelial cells. Mitotic activity is apparent (hematoxylin-eosin, original magnification $\times 40$ ).

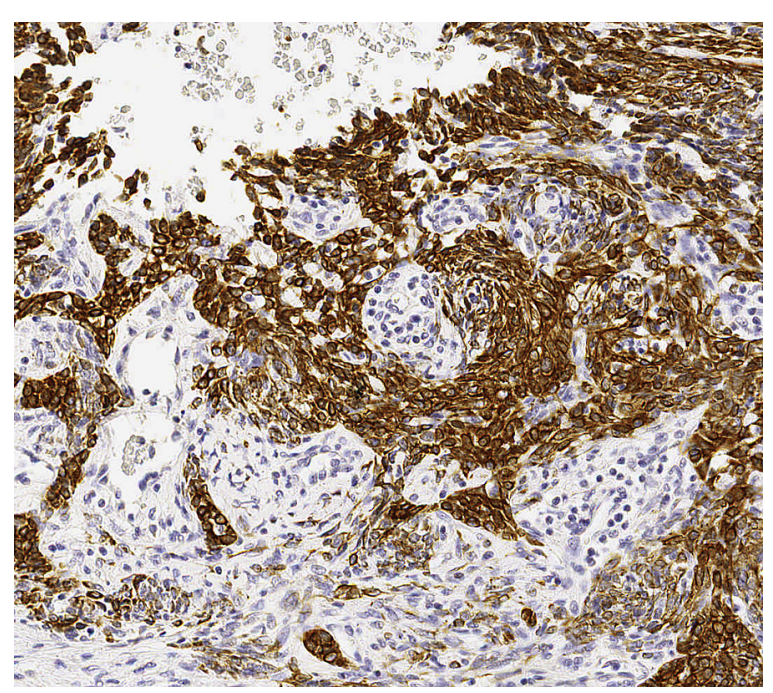

Fig. 8. Photomicrograph showing positive membrane immunohistochemical expression of cytokeratin AE1/AE3 in the ameloblastic epithelium (original magnification $\times 20$ ).

the negative findings from these tests, together with the histologic finding of a focal ameloblastic carcinoma surrounded by considerable nonmalignant tissue, and in agreement with the wishes of the patient's parents, a "wait and see" approach was taken. The patient was followed up every 3 months. After 2 years, there were no clinical or radiologic signs of recurrence or metastasis.

\section{DISCUSSION AND CONCLUSIONS}

Ameloblastic carcinoma is a rare malignant odontogenic tumor that can develop de novo (primary type) or by malignant transformation of an intraosseous or peripheral ameloblastoma (secondary type). ${ }^{5}$ There is as 


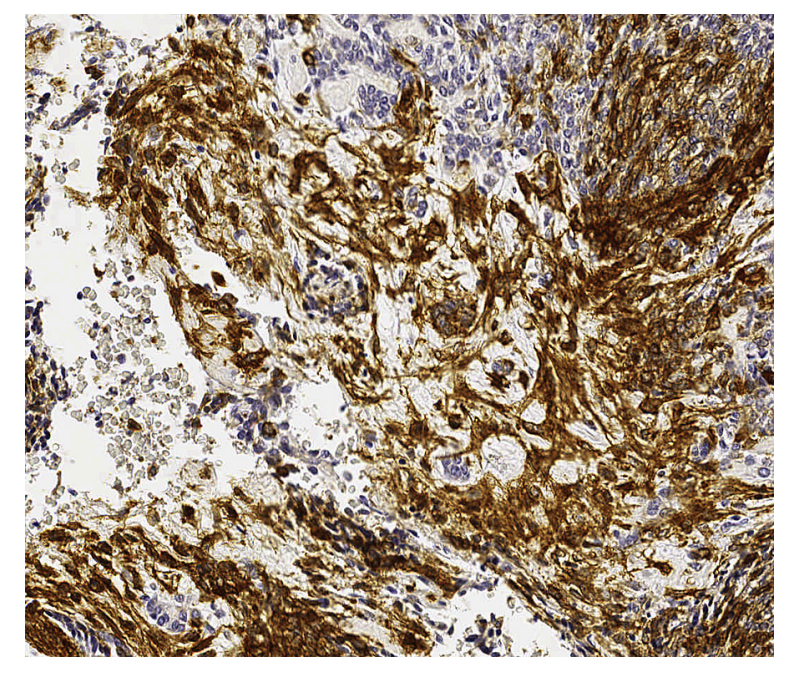

Fig. 9. Positive immunohistochemical reactivity for smooth muscle actin (original magnification $\times 20$ ).

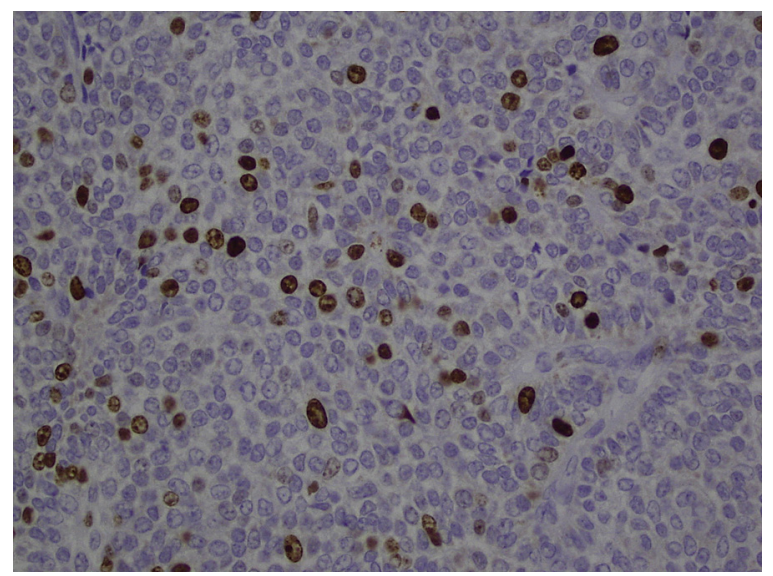

Fig. 10. Focal immunohistochemical reactivity for Ki-67 protein (original magnification $\times 20$ ).

of yet no agreement on whether odontogenic carcinoma can develop from a preexisting odontogenic cyst. In 1984 , Slootweg et $\mathrm{al}^{6}$ presented a case that had probably originated from a keratocyst. In a 2009 review, Yoon et $\mathrm{al}^{7}$ reported 6 cases, none originating from a follicular cyst. In 2012, Pirklbauer et al. ${ }^{8}$ reported an 86-year-old man in whom an ameloblastic carcinoma had appeared at the site from which an odontogenic cyst had been enucleated 10 years previously. A review of the literature in English from 1932 to 2012 found 18 pediatric cases, ${ }^{4,15-26}$ none reportedly originating from a follicular cyst.

Approximately two-thirds of ameloblastic carcinomas involve the mandible. The posterior segments of the jaws are the most frequently affected site. ${ }^{4}$ There is no gender difference in frequency of occurrence. Radiologically, the lesion generally presents as a poorly defined radiolucent lesion with irregular margins. ${ }^{9,10}$
The typical clinical presentation includes expansion of the jaw, rapid tumor growth, pain, paresthesia, perforation of the cortical plate, extension into surrounding soft tissues, and tooth mobility. ${ }^{11}$ The typical clinical course is reported to be aggressive, with extensive local destruction and distant metastatic spread. Metastases preferentially spread via the hematogenous route, but metastatic lymph node involvement has also been reported. The most frequently involved site of metastasis is the lung, although brain and skeletal metastases may also occur. The ameloblastic carcinoma is predisposed to repeated recurrence and thus requires long-term follow-up. ${ }^{3}$

The diagnostic criteria of an ameloblastic carcinoma that has dedifferentiated from ameloblastoma (carcinoma ex ameloblastoma) are based on cytologic atypia and increased mitotic index. Histologic changes include (1) elevated proliferative index (emphasized by high mitotic activity), elevated proliferating cell nuclear antigen expression, and elevated Ki-67 expression; (2) atypia, including nuclear pleomorphism and basilar hyperplasia; (3) hyperchromatism of the nuclei of basaloid cells; and (4) other features of malignancy, such as perineural or perivascular invasion. According to Akrish et al., ${ }^{12}$ histologic findings should be correlated with clinical and biologic features.

In our case, the clinical and histopathologic features were suggestive of an ameloblastic carcinoma. Focal necrosis and atypical mitosis were noted. Irregular islands of odontogenic epithelium were also visible, which aided the diagnosis. There is as yet no general agreement concerning the reactivity of IHC markers as it relates to ameloblastic carcinoma, and findings are discordant. ${ }^{13,14}$ Of interest in this case was the positivity for smooth muscle actin. Recently, Bello et al. ${ }^{13}$ and Kamath et al. ${ }^{14}$ reported on the utility of various epithelial and stromal markers in differentiating ameloblastic carcinoma from ameloblastoma. They noted positive expression of $\alpha$-smooth muscle actin in epithelial islands and stroma, suggesting that the presence of $\alpha$-smooth muscle actin within epithelial islands is highly predictive of ameloblastic carcinoma. However, too few positive cases were reported to reliably use actin in the differential diagnosis.

On conventional radiographs, these lesions present as a poorly defined radiolucent area, similar to an ameloblastoma, but with dispersed radiopacities, apparently due to areas of dystrophic mineralization, which are uncommon in conventional ameloblastoma. ${ }^{13}$

Little is known about the natural history of ameloblastic carcinoma in pediatric patients. Treatment guidelines are not based on results obtained from longterm follow-up, because most case reports cover a period of fewer than 5 years after initial surgical treatment. ${ }^{14} \mathrm{~A}$ review of the literature published in 
Table II. Published cases of ameloblastic carcinoma in pediatric patients (1932-2013)

\begin{tabular}{|c|c|c|c|c|c|c|c|c|c|}
\hline Case & Year & $\begin{array}{l}\text { Study (authors, } \\
\text { reference No.) }\end{array}$ & Age $(y)$ & Site & Gender & Treatment & $\begin{array}{l}\text { Metastases/ } \\
\text { Recurrence }\end{array}$ & Follow-up (то) & Death/Alive \\
\hline 1 & 1932 & Spring $^{17}$ & 5 & Mandible & Male & Not mentioned & Bone & 168 & Death \\
\hline 2 & 1958 & Villa $^{18}$ & 17 & Mandible & Male & Not mentioned & & 0 & Alive \\
\hline 3 & 1971 & Herceg et al. ${ }^{19}$ & 9 & Mandible & Male & Not mentioned & Multiple & 121 & Death \\
\hline 4 & 1977 & Höltje et al..$^{20}$ & 4 & Mandible & Male & Not mentioned & & 36 & Death \\
\hline 5 & 1979 & Krempien et al. ${ }^{21}$ & 5.5 & Maxilla & Male & Surgical (not specified) & Lung & 144 & Alive \\
\hline 6 & 1986 & Nadimi et al. ${ }^{22}$ & 15 & Maxilla & Female & Surgical (not specified) & & 0 & Alive \\
\hline 7 & 1987 & Corio et al. ${ }^{23}$ & 15 & Maxilla & Male & Surgical (not specified) & & 12 & Alive \\
\hline 8 & 1987 & Corio et al. ${ }^{23}$ & 17 & Mandible & Male & Surgical (resection) & Recurrence & 12 & Alive \\
\hline 9 & 2007 & Hall et al. ${ }^{4}$ & 15 & Maxilla & Male & Surgical (enucleated) & Recurrence & 196 & Alive \\
\hline 10 & 2007 & Hall et al. ${ }^{4}$ & 16 & Maxilla & Male & Surgical (resection) & & 288 & Alive \\
\hline 11 & 2007 & Hall et al. ${ }^{4}$ & 7 & Maxilla & Female & Surgical (enucleated) & Recurrence & 119 & Alive \\
\hline 12 & 2007 & Hall et al. ${ }^{4}$ & 17 & Mandible & Female & Surgical (not specified) & Recurrence & 122 & Death \\
\hline 13 & 2008 & Yazici et al. ${ }^{24}$ & 10 & Maxilla & Male & $\begin{array}{l}\text { Surgical (resection }+ \\
\text { radiotherapy }\end{array}$ & & 6 & Alive \\
\hline 14 & 2009 & Reid-Nicholson et al. ${ }^{25}$ & 15 & Mandible & Male & Surgical (resection) & Lymph node & Not specified & Not specified \\
\hline 15 & 2010 & Ndukwe et al. ${ }^{26}$ & 16 & Mandible & Male & Surgical (resection) & & Not specified & Not specified \\
\hline 16 & 2010 & Ndukwe et al. ${ }^{26}$ & 16 & Mandible & Female & Surgical (resection) & & Not specified & Not specified \\
\hline 17 & 2012 & Horváth et al. ${ }^{27}$ & 8 & Mandible & Female & Chemotherapy & Multiple & 8 & Death \\
\hline 18 & 2013 & Yoshioka et al. ${ }^{28}$ & 17 & Mandible & Male & Surgical (enucleation) & Lung/Recurrence & 39 & Death \\
\hline
\end{tabular}

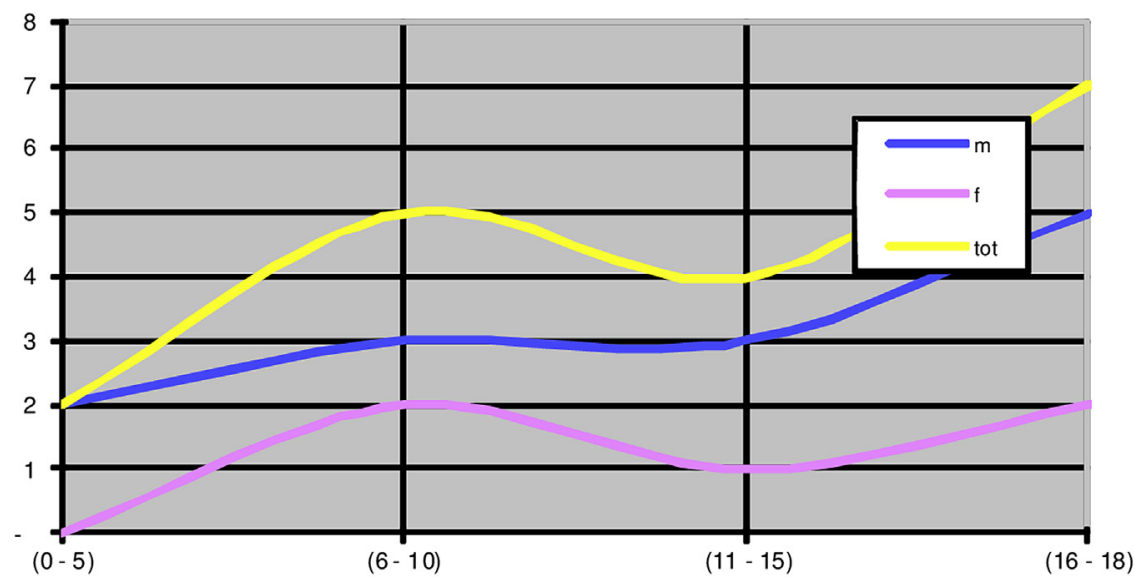

Fig. 11. Age and gender distribution.

English from 1932 to 2012 found 18 pediatric cases of ameloblastic carcinoma. ${ }^{15}$ Data reported included gender, age, location, clinical signs, treatment, followup, recurrence, and metastasis, although not all details were available for every case (Table II). The mean age was 12.6 years, with a wide age range (4 to 17 years). The female-to-male ratio was 1:3 (Figure 11). In 50\% of cases, the first clinical sign was swelling. Other initial signs were pain in $5 \%$, in $5 \%$ it was pain, $6 \%$ dysphonia, and the remaining 39\% unknown or not given (Figure 12). Of all cases, 53\% were in the mandible (Figure 13). During follow-up (mean duration, 7.8 years), local recurrences were detected in 4 of the 18 pediatric patients, and metastasis (both hematogenous and lymphatic) was detected in 4 patients (1 bone, 1 lung, 1 lymph node, and 1 case with multiple metastases). Local recurrences occurred after periods ranging from 1 to 16.3 years, suggesting that long-term follow-up is mandatory.

Since 1979, all cases reported in the literature have been treated surgically. In only 1 case did the patient receive radiotherapy because of the involvement of surgical margins. In another case, chemotherapy was administered.

In contrast to the presentation of ameloblastic carcinoma in the adult, in pediatric patients there is no jaw predilection (53\% mandible). Gender predilection has been reported to be limited in the adult, ${ }^{3,5,12}$ although in our examination of the available literature concerning pediatric patients, we found a male predilection (femaleto-male ratio, 1:3). Clinical presentation in pediatric patients is the same as in adults (see Figure 12).

When ameloblastic carcinoma is diagnosed, nodal and distant metastases must be carefully investigated. 


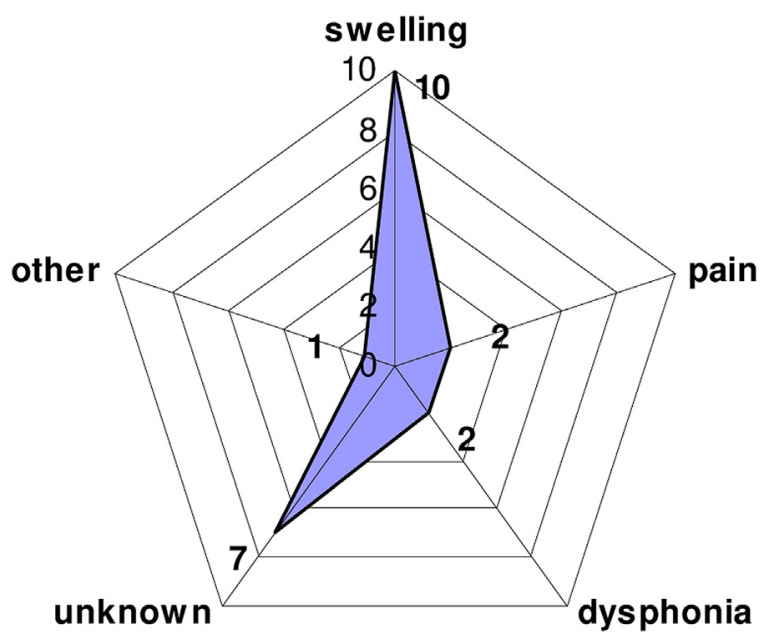

Fig. 12. Distribution of first symptoms.

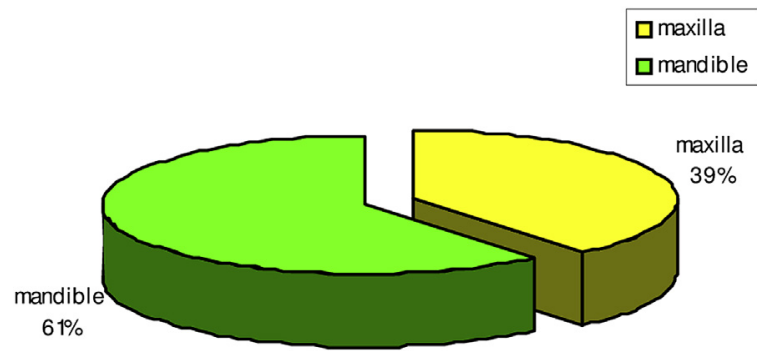

Fig. 13. Primary tumor sites.

Staged work-up comprises a neck examination, head and neck CT scan, chest radiography, and abdominal ultrasonography. Total body CT scanning has also been recommended.

Preoperative radiotherapy has been suggested to decrease tumor size and may be used to treat some rapidly growing tumors before surgery. The radiosensitivity of these tumors has not been investigated in depth, and adjuvant radiation may or may not be indicated. There are few reports on chemotherapy regimens for ameloblastic carcinoma. ${ }^{28}$ However, the role of chemotherapy has not yet been proven. ${ }^{29}$ Avon et al. ${ }^{11}$ suggested both prophylactic and therapeutic contiguous neck dissection. In the case reported here, we adopted a "wait and see" approach, considering the absence of infiltration into the cyst wall, the absence of lymph node metastasis, and the fact that the ameloblastic carcinoma was only present focally, embedded within a larger cyst.

The authors wish to thank John E. Fantasia, DDS, Division of Oral and Maxillofacial Pathology, Long Island Jewish Medical Center, for his assistance.

\section{REFERENCES}

1. Barnes L, Eveson JW, Reichart P, Sidransky D, eds. World Health Organization Classification of Tumours: Pathology and
Genetics of Head and Neck Tumours. Lyon, France: IARC Press; 2005:296-300.

2. Neville BW, Damm DD, Allen CM, Bouquot JE, eds. Oral and Maxillofacial Pathology. 2nd ed. Philadelphia, PA: Saunders; 2009:611-619.

3. Benlyazid A, Lacroix-Triki M, Aziza R, Gomez-Brouchet A, Guichard M, Sarini J. Ameloblastic carcinoma of the maxilla: case report and review of the literature. Oral Surg Oral Med Oral Pathol Oral Radiol Endod. 2007;104:e17-e24.

4. Hall JM, Weathers DR, Unni KK. Ameloblastic carcinoma: an analysis of 14 cases. Oral Surg Oral Med Oral Pathol Oral Radiol Endod. 2007;103:799-807.

5. Lucca M, D’Innocenzo R, Kraus JA, Gagari E, Hall J, Shastri K. Ameloblastic carcinoma of the maxilla: a report of 2 cases. J Oral Maxillofac Surg. 2010;68:2564-2569.

6. Slootweg PJ, Muller H. Malignant ameloblastoma or ameloblastic carcinoma. Oral Surg Oral Med Oral Pathol. 1984;57:168-176.

7. Yoon HJ, Hong SP, Lee JI, Lee SS, Hong SD. Ameloblastic carcinoma: an analysis of 6 cases with review of the literature. Oral Surg Oral Med Oral Pathol Oral Radiol Endod. 2009;108: 904-913.

8. Pirklbauer K, Kozakowski N, Russmueller G, Ewers R, Klug C. Manifestation of an ameloblastic carcinoma ten years after follicular cyst enucleation in the mandibular ramus. J Craniomaxillofac Surg. 2012;40:362-365.

9. Infante-Cossio P, Hernandez-Guisado JM, Fernandez-Machin P, Garcia-Perla A, Rollon-Mayordomo A, Gutierrez-Perez JL. Ameloblastic carcinoma of the maxilla: a report of 3 cases. J Craniomaxillofac Surg. 1998;26:159-162.

10. Karakida K, Aoki T, Sakamoto H, et al. Ameloblastic carcinoma, secondary type: a case report. Oral Surg Oral Med Oral Pathol Oral Radiol Endod. 2010;110:e33-e37.

11. Avon SL, McComb J, Clokie C. Ameloblastic carcinoma: case report and literature review. J Can Dent Assoc. 2003;69:573-576.

12. Akrish S, Buchner A, Shoshani Y, Vered M, Dayan D. Ameloblastic carcinoma: report of a new case, literature review, and comparison to ameloblastoma. J Oral Maxillofac Surg. 2007;65: 777-783.

13. Bello IO, Alanen K, Slootweg PJ, et al. Alpha-smooth muscle actin within epithelial islands is predictive of ameloblastic carcinoma. Oral Oncol. 2009;45:760-765.

14. Kamath KP, Vidya M, Shetty N, Karkera BV, Jogi H. Nucleolar organizing regions and alpha-smooth muscle actin expression in a case of ameloblastic carcinoma. Head Neck Pathol. 2010;4: 157-162.

15. Bruce AB, Jackson T. Ameloblastic carcinoma: report of an aggressive case and review of the literature. J Craniomaxillofac Surg. 1991;19:267-271.

16. Kruse AL, Zwahlen RA, Grätz KW. New classification of maxillary ameloblastic carcinoma based on an evidence-based literature review over the last 60 years. Head Neck Oncol. 2009; $12: 1-31$

17. Spring KL. Gibt es maligne Adamantinome? Oesterr Z Stomatol. 1932;30:455-465 [in German].

18. Villa VG. A case of ameloblastoma evidently undergoing transformation to a new type of tumor. Oral Surg Oral Med Oral Pathol. 1958:11:1148-1157.

19. Herceg SJ, Harding RL. Malignant ameloblastoma with pulmonary metastases. Report of a case and review of the literature. Plast Reconstr Surg. 1972;49:456-460.

20. Höltje WJ, Donath K. Clinical aspects and histomorphology of malignant ameloblastoma. Dtsch Zahnarztl Z. 1977;32:798-802.

21. Krempien B, Brandeis WE, Singer R. Ameloblastoma with metastases in a child: light- and electron microscopic findings. Virchows Arch A Pathol Anat Histol. 1979;381:211-222. 
22. Nadimi H, Toto PD, Jaffe E, McReynolds HD. Basement membrane defect in ameloblastic carcinoma: a case study. J Oral Med. 1986;41:79-81.

23. Corio RL, Goldblatt LI, Edwards PA, Hartman KS. Ameloblastic carcinoma: a clinicopathologic study and assessment of eight cases. Oral Surg Oral Med Oral Pathol. 1987;64:570-576.

24. Yazici N, Karagöz B, Varan A, et al. Maxillary ameloblastic carcinoma in a child. Pediatr Blood Cancer. 2008;50:175-176.

25. Reid-Nicholson M, Teague D, White B, Ramalingam P, Abdelsayed R. Fine needle aspiration findings in malignant ameloblastoma: a case report and differential diagnosis. Diagn Cytopathol. 2009;37:586-591.

26. Ndukwe KC, Adebiyi EK, Ugboko VI, et al. Ameloblastic carcinoma: a multicenter Nigerian study. J Oral Maxillofac Surg. 2010;68:2111-2114.
27. Horváth A, Horváth E, Popşor S. Mandibular ameloblastic carcinoma in a young patient. Rom J Morphol Embryol. 2012;53:179-183.

28. Yoshioka Y, Toratani S, Ogawa I, Okamoto T. Ameloblastic carcinoma, secondary type, of the mandible: a case report. J Oral Maxillofac Surg. 2013;71:58-62.

29. Dhir K, Sciubba J, Tufano RP. Ameloblastic carcinoma of the maxilla. Oral Oncol. 2003;39:736-741.

Correspondence to:

Professor Francesca Angiero

Ospedale San Martino

Largo R Benzi

8 Genova Italy

f.angiero@teos.it, F.angiero@unige.it 